\title{
Nanofibrous Scaffolds Containing Hydroxyapatite and Microfluidic-Prepared Polyamidoamin/BMP-2 Plasmid Dendriplexes for Bone Tissue Engineering Applications
}

This article was published in the following Dove Press journal:

International Journal of Nanomedicine

\begin{abstract}
Mehdi Doosti-Telgerd, (D)
Fatemeh Sadat Mahdavi, ${ }^{2}$

Farzad Moradikhah, ${ }^{3}$

Mohammad Porgham

Daryasari, (D)' Rahimeh Bayrami

Atashgah,' Banafsheh

Dolatyar, (D) ${ }^{4}$ Hamid Akbari

Javar, ${ }^{5}$ Ehsan Seyedjafari, ${ }^{2}$ Iman

Shabani, $\mathbb{D D}^{3}$ Ehsan Arefian, (1D ${ }^{6}$

Farhood Najafi, ${ }^{7}$ Yaser Abdi, ${ }^{8}$

Mohsen Amini ${ }^{9}$

'Department of Pharmaceutical

Biomaterials, Faculty of Pharmacy, Tehran

University of Medical Sciences, Tehran, Iran;

${ }^{2}$ Department of Biotechnology, University

of Tehran, Tehran, Iran; ${ }^{3}$ Department of

Biomedical Engineering, Amirkabir

University of Technology, Tehran, Iran;

${ }^{4}$ Department of Cell and Developmental

Biology, School of Biological Sciences,

College of Science, University of Tehran,

Tehran, Iran; ${ }^{5}$ Department of

Pharmaceutics, Faculty of Pharmacy, Tehran University of Medical Sciences, Tehran, Iran;

${ }^{6}$ Department of Microbiology, School of

Biology, College of Science, University of

Tehran, Tehran, Iran; ${ }^{7}$ Department of Resin

and Additives, Institute for Color Science

and Technology, Tehran, Iran; ${ }^{8}$ Department of Physics, University of Tehran, Tehran, Iran; ${ }^{9}$ Department of Medicinal Chemistry, Faculty of Pharmacy, Tehran University of Medical Sciences, Tehran, Iran
\end{abstract}

Correspondence: Hamid Akbari Javar Department of Pharmaceutics, Faculty of Pharmacy, Tehran University of Medical Sciences, P.O. Box: |4|76|44||, Tehran, Iran

Tel +98 2164I22205

Email akbarijo@tums.ac.ir
Objective: The aim of this study is to fabricate functional scaffolds to gene delivery bone morphogenetic protein-2 (BMP-2) plasmid for bone formation in bone tissue engineering. Methods: Dendriplexes (DPs) of generation 4 polyamidoamin (G4-PAMAM)/BMP-2 plasmid were prepared through microfluidic (MF) platform. The physiochemical properties and toxicity of DPs were evaluated by DLS, AFM, FESEM and MTT assay. In order to create a suitable environment for stem cell growth and differentiation, poly-1-lactic acid (PLLA) and poly-l-lactic acid/poly (ethylene oxide) (PLLA/PEO) scaffolds containing hydroxyapatite nanoparticles (HA) and DPs were fabricated by the electrospinning method. The osteogenic potency of the scaffolds on human adipose tissue-derived mesenchymal stem cells (hASCs) was investigated.

Results: The results revealed that tuning the physical properties of DPs by adjusting flow parameters in microfluidic platform can easily improve the cell viability compared to conventional bulk mixing method. Also, the result showed that the presence of HA and DPs in PLLA/PEO scaffold enhanced alkaline phosphatase (ALP) activity and increased the amount of deposited $\mathrm{Ca}$, as well as, related to osteogenesis gen markers.

Conclusion: This study indicated that on using the MF platform in preparation of DPs and loading them along with HA in PLLA/PEO scaffold, the osteogenic differentiation of hASCs could be tuned.

Keywords: microfluidic, dendriplex, nanofibrous scaffolds, bone tissue engineering

\section{Introduction}

The importance of mesenchymal stem cell (MSC) have been represented in many biomedical engineering studies. The MSC applications can be wider by using the gene delivery systems. ${ }^{1}$ In gene delivery approach, the cells are cultured in an environment (petri dishes, scaffolds) firstly and a designed genes introduced inside the cells for secretion of agents (eg osteoinductive factor) followed by implantation in the injured site. ${ }^{2}$

Many studies have done on the carrier optimization. Although viral vectors have more transfection rate and stable gene expression in comparison to non-viral vectors, ${ }^{3,4}$ but also some critical issues still have remained, including limitation of packaging capacity, induction of immune responses and abnormal gene expression. Some studies have been focused on development of non-viral vectors. 5,6 
Nevertheless, there are some challenges in the way of nonviral vectors development. For instance, they have low transfection efficiency and cytotoxicity effects. Consequently, gene delivery system needs further improvements to promote endosomal escape, transcription and translation of DNA, cell transfection and decrease cytotoxicity. $^{5,7}$ Short half-life of proteins limits tissue engineering and regenerative medicine application field. Most of studies in bone regeneration were applied the naked plasmid DNA encoding a sequence which possess prolonged bioavailability of produced protein, low cost and easy preparation method compared to the direct protein delivery systems. 8,9

Among the non-viral vectors, polyamidoamine dendrimers (eg PAMAM) are one of the most effective vehicles because of prominent characteristics. ${ }^{10}$ Secondary and tertiary amines in the core make positive charged structure at adjusted $\mathrm{pH}$ to form a tight complex with genes and strong "proton-sponge" effect. Besides, there are different generation of them with various range of molecular weight, as well as, commutable peripheral functional groups (e.g amine, hydroxyl, carboxyl etc.) that make more efficient gene transferring via effective cell membrane interaction. ${ }^{11-13}$ It is also used as drug carrier because of its remarkable characteristics (eg high loading capacity of agents, minimal toxicity, high stability and high water solubility and etc.). ${ }^{14,15}$ To improve transfection efficacy and overcoming the challenges of delivery of prepared PAMAM dendriplex (PDP), some PDP surface modifications (eg PEG, cyclodextrin and Larginine) have been performed. ${ }^{11-13,16}$

Although, the main idea of the present study is to fabrication of a scaffold mediated gene delivery system, meanwhile we have gone a step further in improvement of scaffold composite making. For fabrication of polyplexes nanoparticle (PNP) as an additive, microfluidic (MF) technique was chosen to enhance the transfection efficiency and cell viability of PNPs.

In microfluidic devices (MFD), mixing reaction occurs in small Reynolds numbers and consequently it happens based on molecular diffusion. So, it provides a powerful tool for reaction manipulation ${ }^{17}$ and making PNPs with desired physical (size, shape) and chemical characterizations. ${ }^{18}$ One of the other important parameter that has effects on cytotoxicity and transfection efficiency of PNPs is N/P ratio. ${ }^{1}$ Some studies, have shown PNPs prepared by microfluidic method have less cytotoxicity effect compared to the bulk synthesis manner in the same N/P ratio. ${ }^{19}$

Up to now, many studies were done using MFD for preparation of PNPs. Koh et $\mathrm{al}^{20}$ used a MFD for fabrication of polyethylenimine and plasmid DNA nanoparticles (NPs). They showed that MF-prepared PNPs had lower cytotoxicity and better Alkaline phosphatase (ALP) activity and green fluorescent protein (GFP) expression in comparison to bulk synthetized PNPs. Wilson et al fabricated Poly (beta-amino esters)/DNA NPs by a MFD and spontaneously lyophilized those for long term storage. ${ }^{21}$

Poly-l-lactic acid (PLLA), as a FDA approved synthetic polymer, is used as biomaterial in various biomedical applications. Although it has many excellent properties such as biodegradability, biocompatibility and ease of shaping and structures manufacturing process, making acidic byproduct, inflammation response and poor mechanical strength, leading to making PLLA composite mixtures. ${ }^{22}$ PLLA-based scaffold mediated gene delivery system is one of the best multipurpose beneficial approaches for gene transfer. For instance, localization and sustained delivery of genes, ${ }^{23}$ protection of the polyplexes from degradation and clearance at in vivo ${ }^{24}$ are of its advantages.

In this study, electrospun PLLA-based scaffolds combined with MF-prepared PAMAM-BMP-2 dendriplexes were fabricated. We predict that our fabricated gene delivery system can improve osteogenic activity of human adipose tissue-derived mesenchymal stem cells (hASCs) in an in vitro model by means of PLLA-based scaffolds which contains hydroxyapatite nanoparticles (HA) and Dendriplexes (DPs) with desired compactness, size, Polydispersity index (PDI) and highest hASCs viability.

\section{Materials and Methods}

\section{Plasmid DNA Preparation and Extraction}

Plasmid DNA (pCMV6-AC-GFP, OriGene) containing BMP-2 sequence were amplified in Escherichia coli hot strain, DH5 $\alpha$, grown overnight in Luria-Broth base medium containing ampicillin. Then the isolation and purification of plasmid carried out by Qiagen Plasmid Maxi Kit (Qiagen). Ultra-pure water was used to dissolve isolated plasmids in order to determine concentration and purity (UV absorbance ratio at $260 \mathrm{~nm}$ to $280 \mathrm{~nm}$ ) of plasmid DNA by NanoDrop instrument (Thermo Scientific, MA, USA) at $260 \mathrm{~nm}$.

The absorbance ratio at 260 and $280 \mathrm{~nm}$ was 1.93 showing an acceptable plasmid purity and the DNA concentration was determined to be $400 \mu \mathrm{g} / \mathrm{mL}$.

\section{Device Fabrication}

A t-shaped MFD was made by poly (dimethylsiloxane) (PDMS, Sylgard 184, Dow Corning, USA) through soft 
lithography procedure. SU-8 2050 as a negative photoresist (Microchem, Inc.) was spin-coated on 4 inches silicon wafers to make a uniform thickness of photoresist layer and heated. After that, developing stage was done for elimination of uncured photoresist. Then, a PDMS mixture of monomer and curing agent (10:1 weight ratio), was poured on wafer, degassed for $30 \mathrm{~min}$ and cured at $80{ }^{\circ} \mathrm{C}$ for $3 \mathrm{~h}$. After removing of PDMS layer, it was exposed to oxygen plasma (80 mW, $90 \mathrm{~s}$; Diener, Germany) for hydrophilization of PDMS and irreversible bonding to a glass slide. ${ }^{25}$

\section{G4-PAMAM Synthesis}

G4-PAMAM dendrimers were purchased from Institute for Color science and Technology, Tehran, Iran. G4-PAMAM dendrimers with ethylene diamine (EDA) core was synthesis by using the divergent procedure described by Esfand et al. ${ }^{26}$

\section{Nanoparticles Preparation} Dendriplexes of G4 PAMAM/BMP-2 Plasmid Preparation by Conventional Bulk Mixing Method

$50 \mu \mathrm{L}$ of BMP-2 plasmid stock solution (suspension) and $50 \mu \mathrm{L}$ of G4-PAMAM at 4 different concentrations of N/P (where $\mathrm{N}=$ molar number of primary amines in the G4-PAMAM and $\mathrm{P}=$ molar number of phosphate groups in pDNA backbone), $\mathrm{N} / \mathrm{P}=5,7,10$ and 15 were shaken followed by mixing with constant rate and brief vortex for 30 seconds. The DPs preparation was based on self-assembly due to electrostatic forces.

\section{Dendriplexes Preparation by Microfluidic System} Hydrodynamic flow focusing MFD (consist of channels with $40 \mu \mathrm{m}$ height and $200 \mu \mathrm{m}$ width) used in this study is a t-junction PDMS chip having three inlets, two inlets (side inlets) are related to PAMAM solution and the third one (central inlet) was for plasmid solution, and one outlet (30 mm length) for prepared DPs.

For MF preparation of DPs, $10 \mu \mathrm{g} / \mathrm{mL}$ of plasmid solution was prepared and was applied associated with different concentration of PAMAM in 4 different $\mathrm{N} / \mathrm{P}$ ratio $(5,7,10$ and 15$)$ and introduced to chip. Two syringe pumps were employed to change the flow ratio (FR) PAMAM solution to plasmid solution (1, 5, 10 and 13) resulting in regulating the focused flow width.

\section{Gel Retardation Assay}

Gel retardation assay was carried out to determine the DNA condensation. $10 \mu \mathrm{g} / \mathrm{mL}$ of plasmid solution was prepared and applied associated with different concentration of PAMAM in 5 different N/P ratio $(0.5,1,2,3$ and 5$)$ and introduced to chip. Then the solution containing DPs were mixed with loading buffer and loaded on agarose gel $(0.8 \% \mathrm{w} / \mathrm{v})$ for electrophoresis for $40 \mathrm{~min}$. Finally, gel retardation photographed by UV light.

\section{Scaffolds Fabrication Method}

PLLA (Average $M_{W}$ 240,000) and PEO (Average $M_{W}$ 900,000) were purchased from Sigma-Aldrich. Different types of PLLA and PLLA/PEO- based scaffolds containing HA and DPs were prepared by electrospinning technique.

Electrospinning was performed in horizontal set up, equipped with two nozzles and needle gauge of 24 , flow rate of $0.5 \mathrm{~mL} / \mathrm{h}$ with tip-collector distance of $15 \mathrm{~cm}$. The applied voltage was $18 \mathrm{kV}$ and speed of rotary collector was $400 \mathrm{rpm}$. Electrospinning parameters were kept constant during preparation of all type of nanofibrous scaffolds. To avoid aggregation of DPs alongside scaffolding process, after fabrication of DPs, $2 \%$ of Terhalose (Sigma-Aldrich) was added to the prepared DPs and flash freeze technique was carried out and ultimately freeze dried (Christ, Germany) for $48 \mathrm{~h}$.

\section{Preparation of PLLA and PLLA/DP Solution}

To prepare PLLA solution in chloroform/DMF (Merck), 0.43 $\mathrm{g}$ of PLLA $(7 \% \mathrm{w} / \mathrm{v})$ was dissolved in $6 \mathrm{~mL}$ of chloroform under constant stirring. After that, the optimized amount of DMF ( $1 \mathrm{~mL}$ ) was added to the obtained PLLA transparent solution. Then the solution was used for electrospinning.

DPs incorporated PLLA scaffolds (PLLA/DP) was prepared after DPs were dispersed about 30 seconds in $1 \mathrm{~mL}$ of DMF and added to the prepared PLLA solution in chloroform.

Preparation of PLLA/HA and PLLA/HA/DP Solution To prepare PLLA/HA solution, $0.43 \mathrm{~g}$ of PLLA (7\% w/v) was dissolved in $6 \mathrm{~mL}$ of chloroform under constant stirring. Then, HA $(5 \% \mathrm{w} / \mathrm{v})$ was dispersed in $1 \mathrm{~mL}$ DMF by sonication for $30 \mathrm{~min}$ and then added into stirring solution and employed for scaffolding by electrospinning.

The prepared DPs was dispersed about 30 seconds and added to dispersed HA in $1 \mathrm{~mL}$ of DMF. PLLA/HA/DP scaffolding condition was similar to above mentioned.

\section{Preparation of PLLA/PEO and PLLA/PEO/DP Solution}

To prepare PLLA/PEO solution, the ratio of PEO/PLLA was selected $10 \%$. The polymers were dissolved in $6 \mathrm{~mL}$ of chloroform under stirring, then $1 \mathrm{~mL}$ of DMF was 
added to the solution and the prepared solution used for PLLA/PEO scaffolding by electrospinning.

PLLA/PEO/DP scaffold was obtained by electrospinning after DPs were dispersed about 30 seconds in $1 \mathrm{~mL}$ of DMF and added to the prepared PLLA/PEO solution in chloroform.

\section{Preparation of PLLA/PEO/HA and PLLA/PEO/HA/DP Solution}

To prepare PLLA/PEO/HA solution, 5\% of HA were dispersed under sonication for $30 \mathrm{~min}$ at $1 \mathrm{~mL} \mathrm{DMF}$, then were mixed with prepared PLLA/PEO solution in chloroform.

To fabricate the PLLA/PEO/HA/DP scaffold, the prepared DPs was added and dispersed 30 seconds in dispersed HA in $1 \mathrm{~mL}$ of DMF. Then the obtained mixture was added to the PLLA/PEO solution. Scaffolding condition was similar to mentioned above.

\section{Characterization}

Structural investigation of DPs was carried out by FESEM, AFM and DLS. Cytotoxicity tests were assessed by MTT calorimetric assay.

Field Emission Scanning Electron Microscopy Imaging (FESEM)

Fabricated DPs and prepared nanofibrous morphology was observed by FESEM (FEI NOVANANOSEM 450, USA) imaging at $10 \mathrm{kV}$. All samples were fixed on aluminum stub and sputtered by a thin layer $(10 \mathrm{~nm})$ of gold.

\section{Dynamic Light Scattering Technique (DLS)}

To determine particle size and PDI of prepared DPs, dynamic light scattering technique were used (Zetasizer NanoZS, Malvern Instrument, Germany). The source of electromagnetic waves was He-Ne laser with $633 \mathrm{~nm}$ excitation wave length. Triplicate of diluted of DPs was used to determined size and PDI by capillary flow at $25^{\circ} \mathrm{C}$.

\section{Evaluation of Cell Viability by MTT Assay}

To evaluate in vitro cytotoxicity of DPs and PAMAM, PAMAM and fabricated DPs by different ratio of N/P (5, 7,10 , and 15 ) added to $5 \times 10^{3}$ passage 3 of hASCs (purchased from the Royan Institute, Tehran, Iran) were seeded in standard cell culture condition $\left(5 \% \mathrm{CO}_{2}\right.$ at $37^{\circ} \mathrm{C}$, in (DMEM) and $10 \%$ (v/v) FBS with other supplements) on 96 well plate. After determined time points ( 24 and $72 \mathrm{~h}$ ), the upper medium was removed and rinsed by PBS, then substituted with DMEM including 10\% MTT reagent and incubated for 4 hours at standard condition. Cell viability of DPs and PAMAM was determined by measuring the absorbance of dissolved formazan crystals by DMSO at $570 \mathrm{~nm}$ wavelength. The assay repeated at least three times. The results were reported as means $\pm \mathrm{SD}$.

\section{Cell Transfection Efficacy Screenings}

hASCs were applied to analyze in vitro gene transfection. After $12 \mathrm{~h}$ of cell seeding in 4 -well plate at $2 \times 10^{4}$ cell density in each well, the prepared NPs with $10 \mathrm{~N} / \mathrm{P}$ ratio containing $1 \mu \mathrm{g}$ GFP plasmid DNA (pCDH-CMV-MCSEF1- copGFP from System Biosciences, USA) was transferred into the well. Culture media were refreshed after $4 \mathrm{~h}$ of incubation and the cells were incubated for additional $24 \mathrm{~h}$. Finally, the cells were washed by PBS $(\mathrm{PH}=7.4)$ and imaged by fluorescent microscopy.

\section{Cell Proliferation Assay}

To evaluate cell attachment and proliferation on the scaffolds, circular shape scaffolds (1.5 $\mathrm{mm}$ in diameter) were sterilized by ethanol $70 \%$ in tissue culture plate, washed with PBS and incubated with basal medium (DMEM supplemented with $10 \%$ FBS). Then the cell suspension containing $5 \times 10^{3}$ cell density was seeded on scaffold. At the same manner with DPs cell viability evaluation.

\section{Osteogenic Differentiation}

About $10^{4}$ cell density $/ \mathrm{cm}^{2}$ (reached $80 \%$ confluence) seeded on scaffolds were maintained on $100 \mathrm{nM}$ dexamethasone, $0.2 \mathrm{mM}$ ascorbic acid 2-phosphate, and $10 \mathrm{mM} \beta$-glycerophosphate (Sigma-Aldrich) to analysis osteogenic differentiation.

\section{Alkaline Phosphatase Activity Assay}

ALP activity colorimetric assay kit (Parsazmoon, Tehran, Iran) was applied to confirm osteogenic differentiation of cells by scaffolds at days 7,14 and 21. About $250 \mathrm{~mL}$ of radio immunoprecipitation assay (RIPA) buffer was used to lyse the cells. The lysate was shaken at $4{ }^{\circ} \mathrm{C}$ for $1 \mathrm{~h}$, centrifuged at $15,000 \mathrm{rpm}$ for $15 \mathrm{~min}$. After that $20 \mu \mathrm{L}$ of supernatant was added to P-nitrophenyl phosphate which changes by ALP activity to yellow color. The ALP enzyme activity (IU/L) was normalized against the total protein $(\mathrm{mg} / \mathrm{dl})$ which measured at $570 \mathrm{~nm}$ wavelength by absorbance reader.

\section{Calcium Content Assay}

Calcium assay kit (Parsazmoon, Tehran, Iran) was applied in order to determine the calcium concentration at days 7 , 14 and 21. The scaffolds contained cells were homogenized in $0.6 \mathrm{~N} \mathrm{HCl}$, shaken at $4^{\circ} \mathrm{C}$ for $1 \mathrm{~h}$. The calcium 
concentration was determined based chromogenic complex formation between calcium ions and Cresolphtalein by serial dilution of standard solution in the kit. The optical density of complex was measured at $575 \mathrm{~nm}$ wavelength by absorbance reader.

\section{Quantitation of Gene Expression by Real- Time PCR}

Total RNA was extracted at days 7 and 14 and converted to cDNA. Real-time polymerase chain reaction (PCR) was administered using 1X SYBR Premix Ex TaqII on iCyler IQ5 (Bio-Rad, CA, USA), employing a continuous fluorescence-detecting thermal cycler, Rotor Gene Q Sequence Detection System (Qiagen, Hilden, Germany). The primer sequences are listed in Table 1. Quantification was performed by the standard curve method using REST-RG software, and data were normalized relative to the $\beta$-actin housekeeping gene.

\section{Statistical Analysis}

All results are reported for three and more experiments as the mean \pm SD. Statistical significance analysis was determined by GraphPad prism 8.0. The two-way ANOVA was used to assess the significant differences.

\section{Result and Discussion}

\section{Microfluidic-Prepared Dendriplexes}

The size and size distribution of DPs will affect the biological activity such as toxicity and transfection efficacy of designed delivery systems. ${ }^{27}$ Hydrodynamic flow focusing MFD was utilized to preparation of PAMAM/BMP-2 plasmid dendriplexes due to microfluidic platform advantages in compacting DNA/cationic polymers including: smaller diameters and improved nanoparticle stability as well as more favorable cellular viability and increased transfection. ${ }^{21}$ The used MFD for preparation DPs is t-shape and has tree inlets, two inlets (side inlets) for PAMAM solution and one inlet (central inlet) for plasmid solution, and one outlet (30 mm length) for prepared DPs. Fluorescein isothiocyanate (FITC) dye $\left(1 \mathrm{mg} / \mathrm{mL}^{-1}\right)$ was used to visualization hydrodynamic flow focusing ability, and imitate plasmid solution by an inverted fluorescence microscope (Micros, Austria). As shown in Scheme 1, water flow $(20 \mu \mathrm{L} / \mathrm{min})$ from lateral channels hydrodynamically has focused the FITC dye solution ( $2 \mu \mathrm{L} / \mathrm{min})$ to a tightly focused flow.

The complexation between plasmid and PAMAM are driven by kinetics caused by strong electrostatic interactions. ${ }^{28}$ In this system, PAMAM due to higher diffusion constant $\left(\approx 10^{-10} \mathrm{~m}^{2} \mathrm{~s}^{-1} \text { at } 25^{\circ} \mathrm{C}\right)^{29}$ than plasmid $\left(\approx 10^{-12} \mathrm{~m}^{2} \mathrm{~s}^{-1}\right.$ at $\left.25^{\circ} \mathrm{C}\right),{ }^{30}$ diffuse to the focused stream and after that DPs is fabricated.

The MF approach is based on the interfacial strength between streams, wherein these this forces have principal role in physicochemical characteristics of NPs (such as size and size distribution). Chen et al. ${ }^{31}$ found out that the interfacial strength depends on the flow ratio of the stream of the lateral channels to the central channel which in turn increases the flow ratio resulting in a reduced size and size distribution of NPs. It is hypothesized that by change in FR one can adjust size and size distribution of NPs. Figure 1A and B demonstrated the DLS results of DPs. These results indicated that by FR increase from 5 to 13, particle size and PDI reduced from $389 \pm 30 \mathrm{~nm}, 0.35 \pm 0.08$ to $210 \pm 16 \mathrm{~nm}, 0.2 \pm 0.01$ respectively. Furthermore, size and morphology DPs investigated by FESEM and AFM methods and images analyzed by ImageJ software (Figure 2). This results showed that average of DPs size is $\approx 70 \mathrm{~nm}$ and data both methods have good correlation.

\section{Evaluation of DNA Binding Ability}

Negatively charged pDNA can be compacted by cationic vectors, such as PAMAM through electrostatic interaction (Figure S1). Agarose gel retardation assessment can be used as an indicator of the ability of PAMAM to condense pDNA at different N/P ratios. Based on our results, the mobility of the pDNA retarded at an $\mathrm{N} / \mathrm{P}=1$ or greater. Hence, N/P ratios of 1 or above were chosen for further studies.

Table I List of the Primer Sequences

\begin{tabular}{|l|l|l|}
\hline Gene & Forward & Reverse \\
\hline BMP-2 & TCTGACTGACCGCGTTACTC & TCTCTGTTTCAGGCCGAACA \\
ALP & CAA CAG GGT AGA TTT CTC TTG G & GGT CAG ATC CAG AAT GTT CC \\
OPN & GCC GAG GTG ATA GTG TGG TT & TGA GGT GAT GTC CTC GTC TG \\
$\beta$-Actin & ATG CCT GCC GTG TGA AC & ATC TTC AAA CCT CCA TGA TG \\
\hline
\end{tabular}



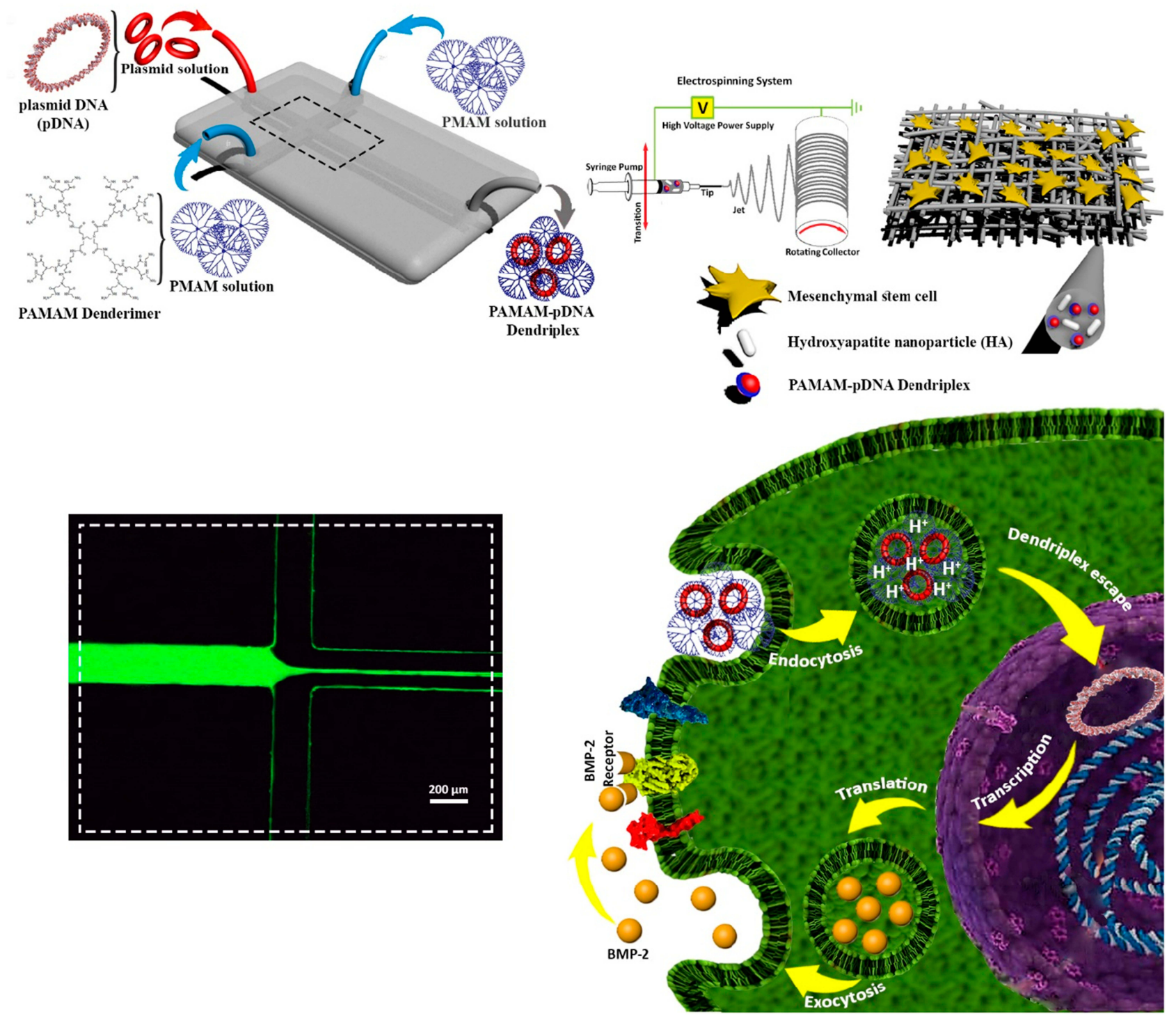

Scheme I Schematic representation of MF preparation of DPs, scaffolds fabrication, transfection mechanism of DPs, release mechanism of BMP-2 and fluorescence image of the FITC stream which hydrodynamically focused with water (scale bar $200 \mu \mathrm{m}$ ).

\section{MTT Assay of Dendriplexes and PAMAM}

Cytotoxicity of the vector or vector/pDNA DPs used for gene delivery applications was evaluated. As shown in Figure 3, MTT Assay was used to investigation cytotoxicity of NPs (bulk and microfluidic at N/P $=5,7,10$ and 15 ) and PAMAM toward hASCs in two time point (24 and $72 \mathrm{~h}$ ) at $37{ }^{\circ} \mathrm{C}$.

The bulk and MF-prepared DPs exhibit N/P-dependent cytotoxicity. The toxicity (for bulk and MF-prepared DPs) was observed to be increased with increasing in N/P ratios (PAMAM concentration), supporting that the high amount of free PAMMA can cause cell death. PAMAM cytotoxicity followed similar pattern.
The MF fabricated DPs toward bulk prepared DPs (in same N/P ratios) displayed higher cell viability, corresponding to the lowest toxicity. Increase cell viability observed in MF method could be due more compacting plasmid and PAMAM resulting in less number of free PAMAM. ${ }^{20}$ This data showed that the MF could be improved the cytocompatibility of DPs, which is useful for safe gene delivery applications.

\section{Cell Transfection Efficacy Screenings}

Entry of NPs formed through microfluidic mixing into hASCs, were assessed using GFP expression after $24 \mathrm{~h}$ exposure. As shown in Figure S2, it was well-displayed 

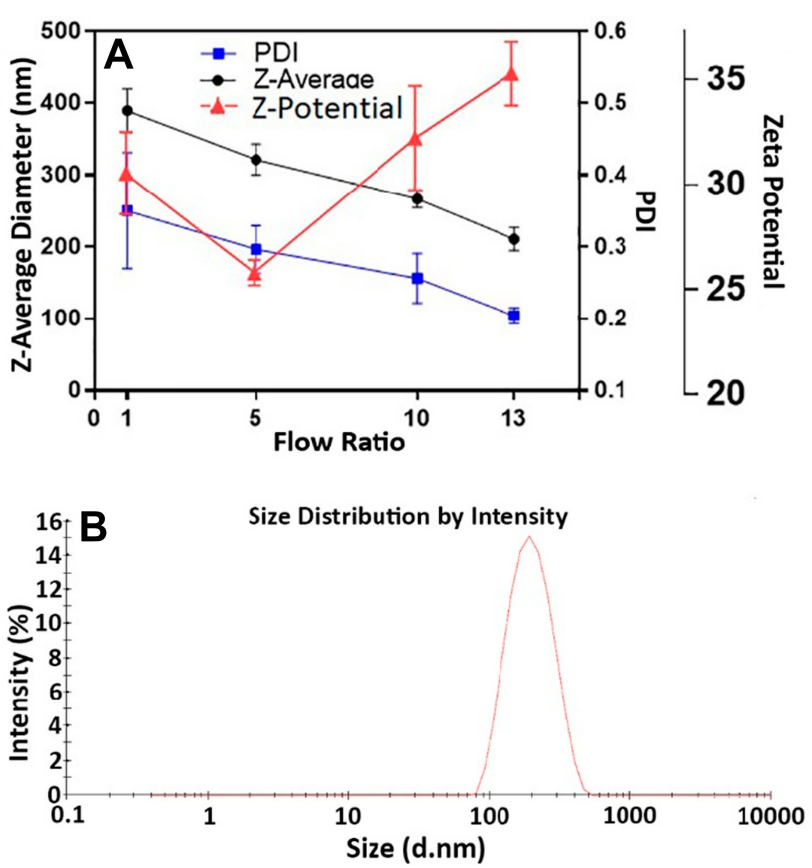

Figure I (A) Effect FR on DPs size and PDI based on DLS result. (B) Size distribution by intensity DPs at N/P ratio 10 and flow ratio 13.

that the cellular uptake of prepared NPs was been successful based on fluorescence microscopy images.

\section{FESEM and EDX Analysis of Scaffolds}

The scaffolds PLLA, PLLA/HA, PLA/DP, PLLA/HA/DP, PLLA/PEO, PLLA/PEO/HA, PLLA/PEO/DP and PLLA/
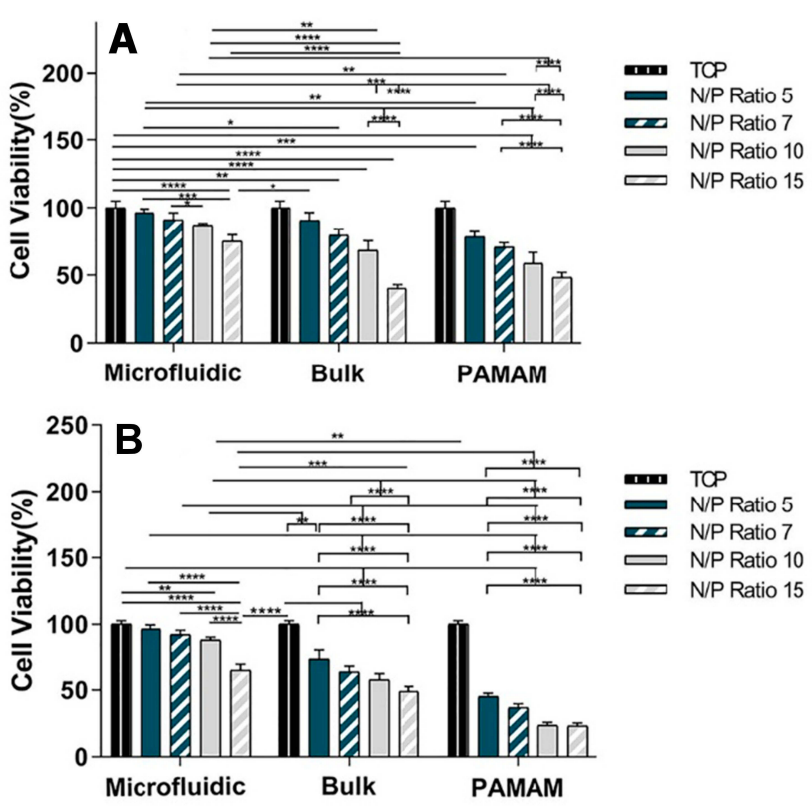

Figure 3 Evaluation of in vitro cell cytotoxicity by MTT assay (A) after I and (B) 3 days of cell growth induced by DPs prepared with conventional bulk method and MFD method compared to PAMAM dendrimers, respectively, mean \pm SD. Notes: $* \mathrm{P}<0.05, * * \mathrm{P}<0.01$, $* * * \mathrm{P}<0.001$ and $* * * * \mathrm{P}<0.0001$.

PEO/HA/DP were fabricated and FESEM images of these scaffolds are shown in Figure 4. It could be seen that all scaffold structures are porous with interconnected pore among the nanofibers. Furthermore, in all cases bead-free nanofibers were obtained. ImageJ software analysis showed that adding PEO to PLLA scaffolds enhanced
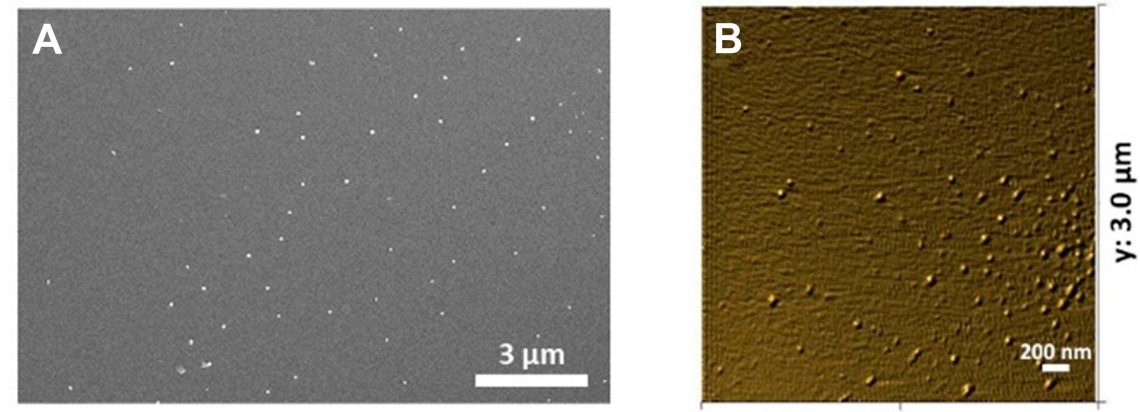

$\mathrm{x}: 3.0 \mu \mathrm{m}$

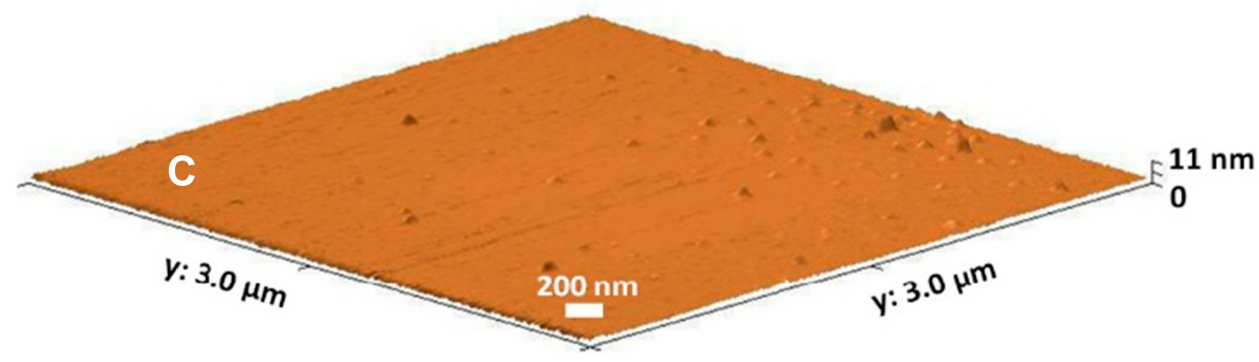

Figure 2 Morphology analysis of prepared DPs by microfluidic platform at the N/P ratio of I0, (A) Representative field emission scanning electron microscopy (FESEM), scale bar $3 \mu \mathrm{m}$, (B) Surface topography of DPs, 2D AFM imaging, (C) 3D AFM imaging, scan size $3 \times 3 \mu \mathrm{m}$. 

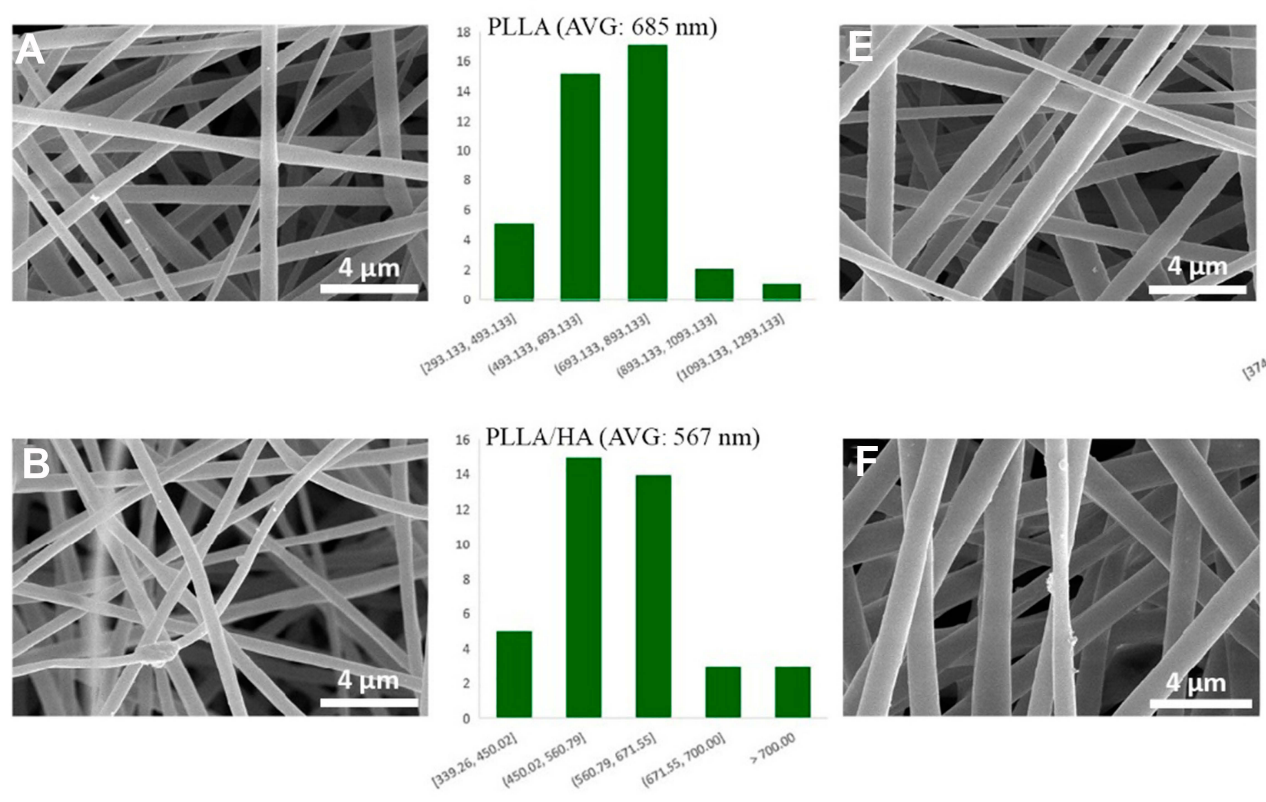

18 PLLA/PEO (AVG: $828 \mathrm{~nm}$ )

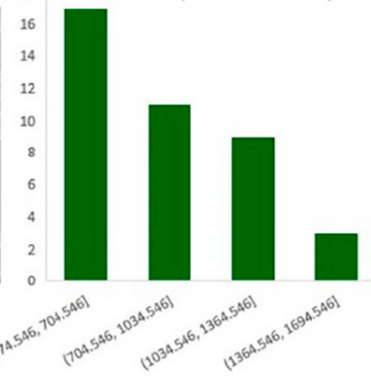

PLLA/PEO/HA (AVG: $1191 \mathrm{~nm}$ )
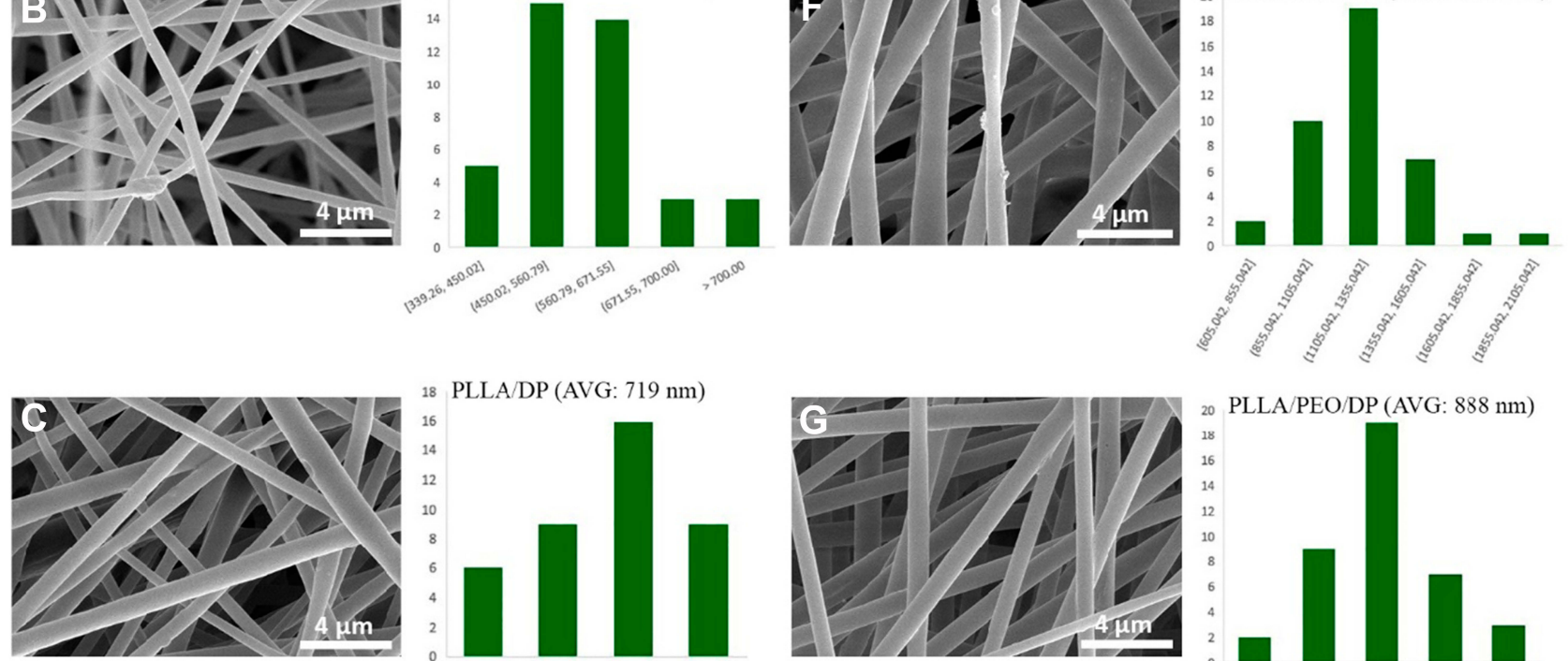

18 PLLA/DP (AVG: $719 \mathrm{~nm}$ )
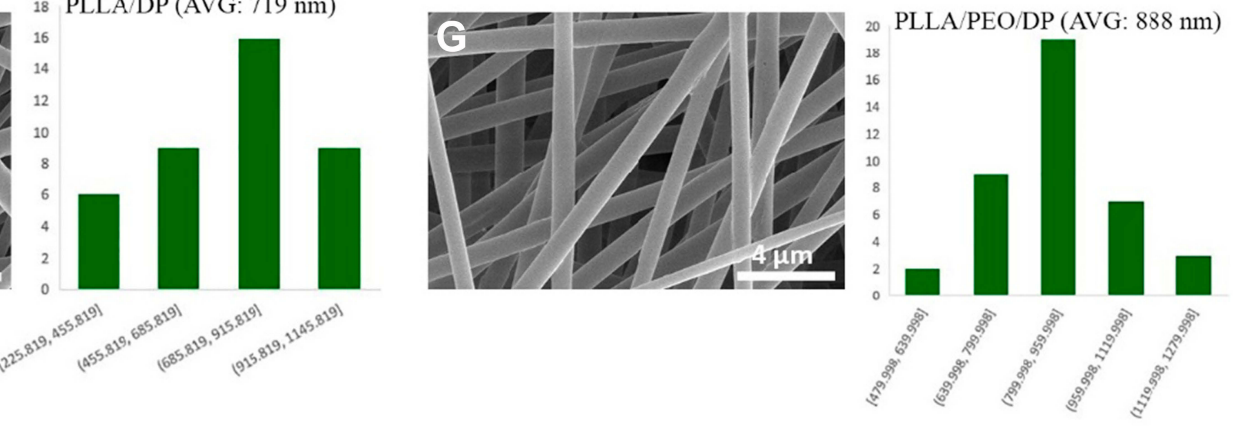

25 PLLA/PEO/HA/DP (AVG: 895nm)
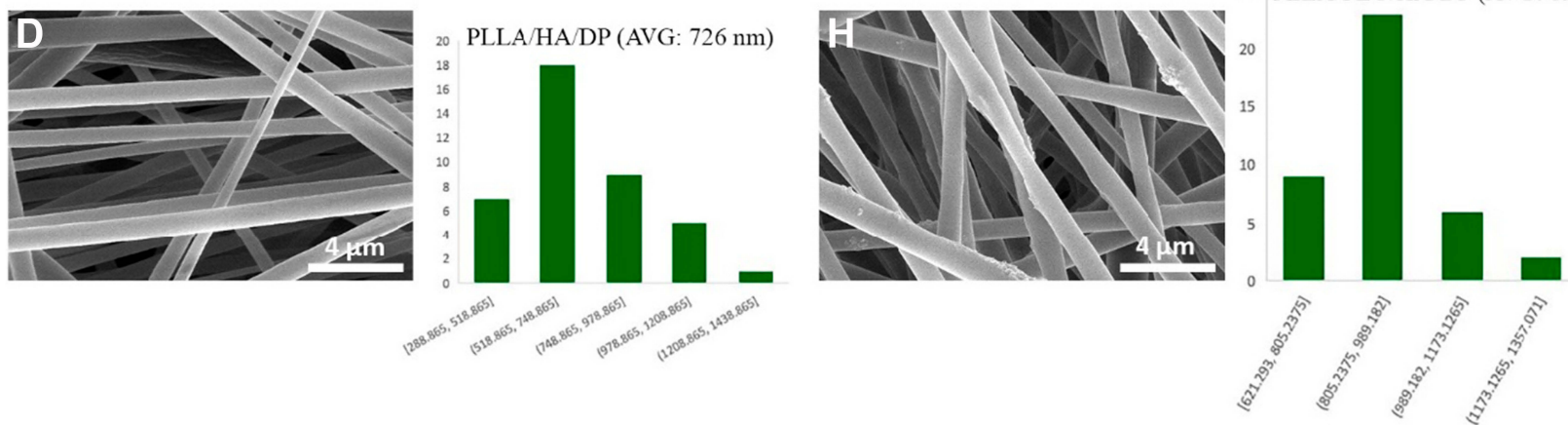

Figure 4 FESEM imaging and ImageJ analysis of electrospun nanofibrous scaffolds: (A) PLLA, (B) PLLA/HA, (C) PLLA/DP, (D) PLLA/HA/DP, (E) PLLA/PEO, (F) PLLA/PEO/ HA, (G) PLLA/PEO/DP, (H) PLLA/PEO/HA/DP nanofibrous structure, scale bar, $4 \mu \mathrm{m}$.

average thickness of nanofibers. This result proved that the stretch of free volume befalls on combining the two polymers. The conformation differences between PLLA segments in PLLA/PEO blends reduces chain compactness in comparison to alone PLLA and consequently higher fiber diameters were seen. ${ }^{32}$
Figure 5 illustrated the EDX analysis and elemental mapping of scaffolds PLLA/DP, PLLA/PEO/DP and PLLA/PEO/HA/DP related to the quantitative and qualitative elemental analysis to prove presence and distribution HA and DPs within PLLA/PEO/HA/DP scaffold and DPs within these three scaffolds. In addition, $\mathrm{Ca}$ and $\mathrm{P}$ presence 

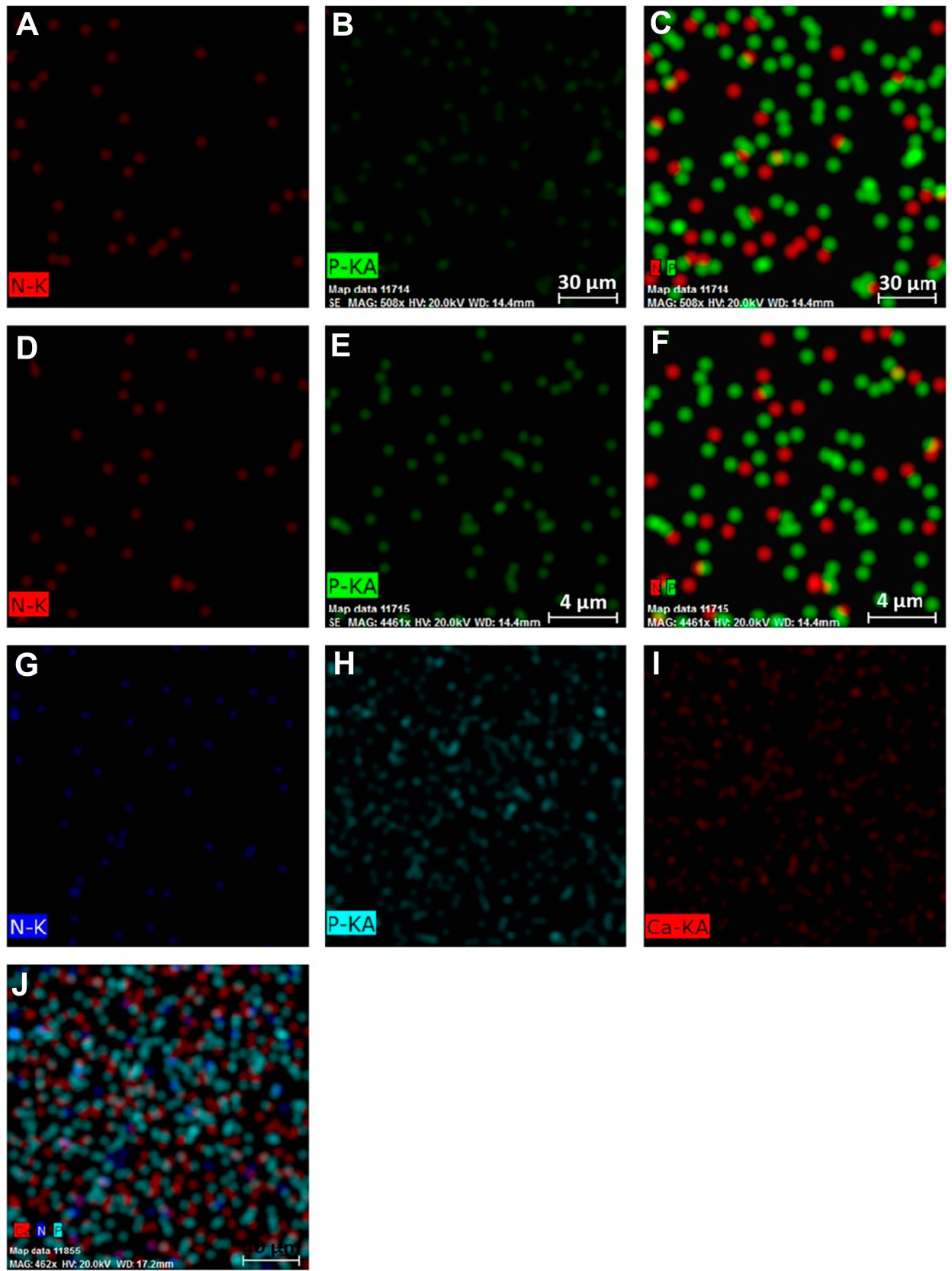

Figure 5 The EDX elemental mapping of PLLA/DP corresponding (A) nitrogen, (B) phosphor, (C) nitrogen and phosphor, elemental mapping of PLLA/PEO/DP corresponding (D) nitrogen, (E) phosphor, (F) nitrogen and phosphor, and elemental mapping of PLLA/PEO/HA/DP corresponding (G) nitrogen, (H) phosphor, (I) calcium, (J) nitrogen, phosphor and calcium.

indicated the existence of HA, as well as, $\mathrm{N}$ and $\mathrm{P}$ element related to DPs.

\section{Tensile Strength}

The mechanical properties of the nanofibrous scaffolds applied in bone tissue engineering is crucial key factor because the scaffold requires to endure stress accompanied by in vitro culture and in vivo implantation. As shown in Figure 6A, average tensile stress PLLA scaffolds are $1.5 \pm$
0.3 MPa. After incorporation HA and DPs into PLLA, the average tensile strength enhanced, which were higher than that of PLLA ones. As respect, the average elongation at break of the PLLA/HA, PLLA/DP and PLLA/HA/DP hybrid scaffolds were lower than pure PLLA. Therefore, increment of HA and DPs raised mechanical strength of PLLA scaffolds. As well as, similar results were observed for the PLLA/ PEO scaffolds, see Figure 6B. These results indicated that HA and DPs operate like a considerable reinforcement on 

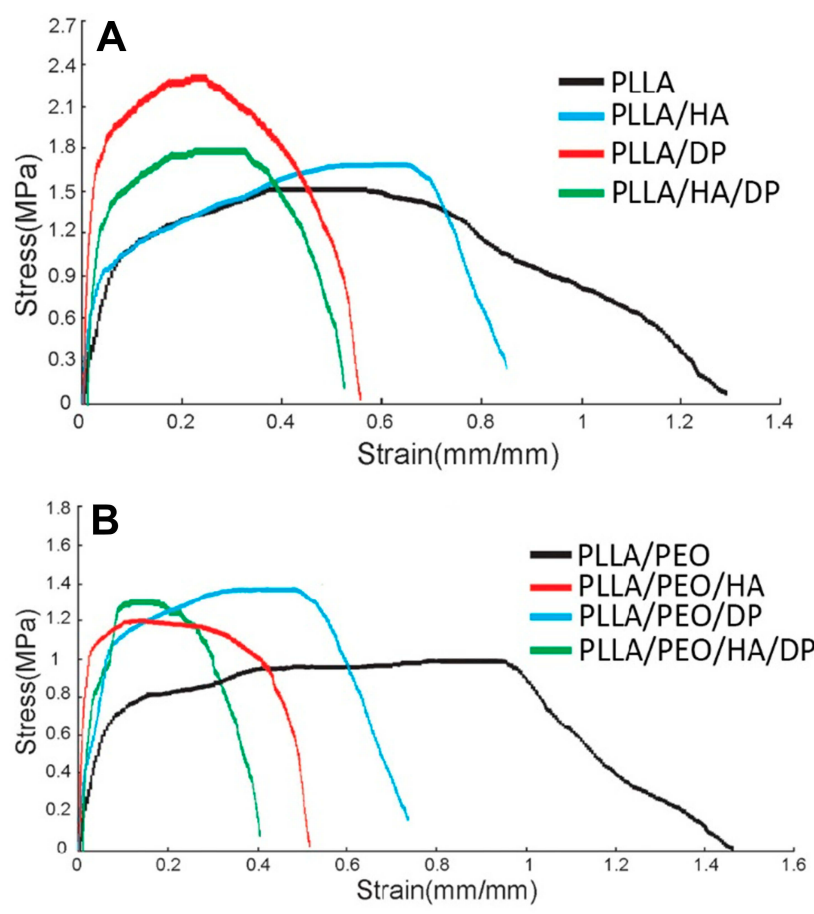

Figure 6 Tensile strength of (A) PLLA and (B) PLLA/PEO based scaffolds.

both PLLA and PLLA/PEO nanofiber scaffolds. ${ }^{33}$ Probably the reason of this phenomenon for influence DPs on stressstrain curve could explain by increased possibility hydrogen bonding between $\mathrm{NH}_{2}$ groups DPs and oxygen atoms ester groups PLLA chains. These hydrogen bonding could increase tensile strain and decrease the average elongation at break of the PLLA and PLLA/PEO fiber scaffolds. ${ }^{34}$

Besides, Figure $6 \mathrm{~A}$ and $\mathrm{B}$ indicated that tensile strength of PLLA decreased with adding PEO, whiles the elongation at break enhanced. This could be related to the attendance of PEO enhancing the segmental mobility of PLLA chains which increase rubbery nature of PLLA in PLLA/PEO scaffolds. ${ }^{35}$

\section{Cell Attachment and Proliferation}

MTT assay was utilized to investigate the cell affinity to nanofibrous scaffolds, see Figure 7A. The results demonstrated that cell viability of scaffolds decreased gradually by incubation period from 1 to 5 days (except PLLA, PLLA/PEO and PLLA/PEO/HA on the 5th day of the treatment). This observation probably proved that the polymer matrix could decrease cell viability. Embedding of DPs to scaffolds significantly decreased cell viability, may be due to release of DPs from DP-containing scaffolds. ${ }^{36}$

Another trend observed from Figure 7A is that incorporation of HA into scaffolds enhanced cell viability of PLLA and PLLA/PEO scaffolds, while a significant difference can be observed in PLLA/HA/DP and PLA/PEO/ HA/DP scaffolds. This observation indicated that cytotoxicity could be generated from release of DPs and following that transfection to hASCs, but not from $\mathrm{HA}^{33,37}$
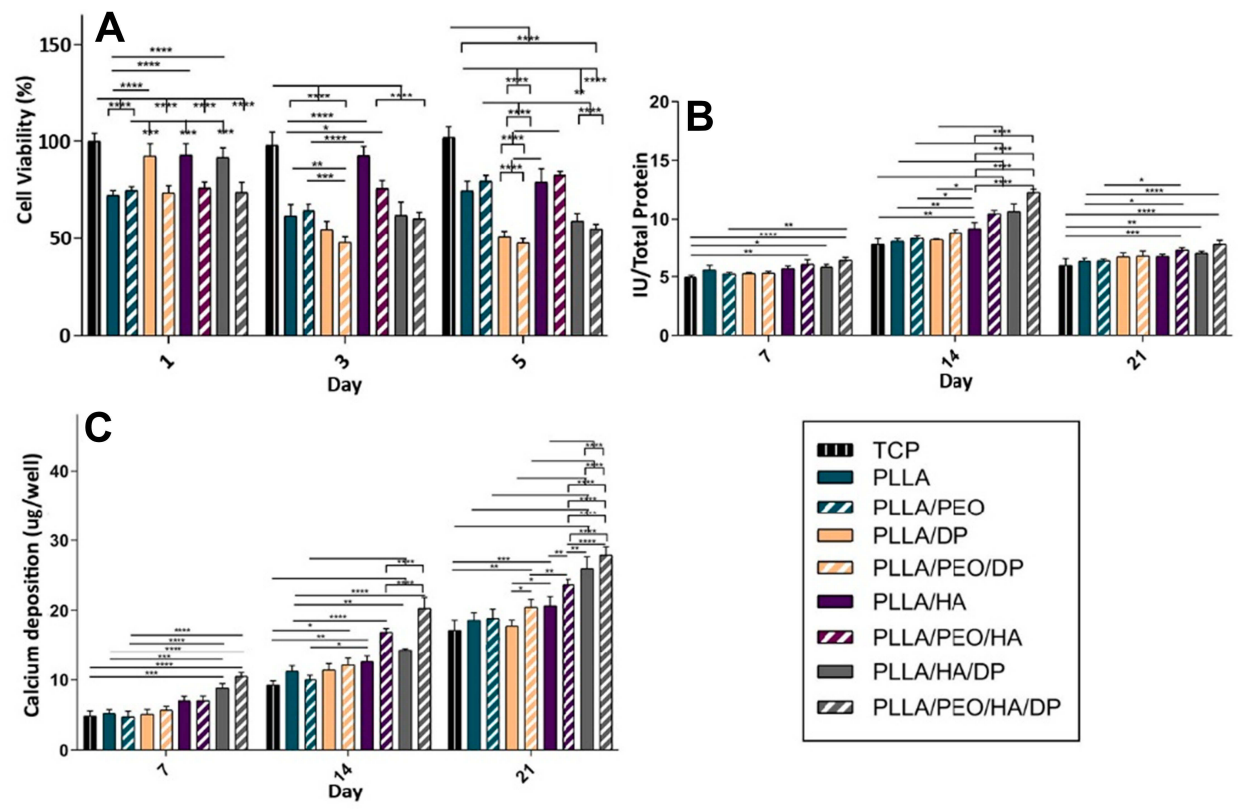

Figure 7 Evaluation of in vitro cell cytotoxicity by $(\mathbf{A})$ MTT assay, (B) ALP activity and (C) Ca deposition. Results were expressed as a mean \pm SD. Notes: ${ }^{*} \mathrm{P}<0.05$, $* * \mathrm{P}<0.01$, $* * * \mathrm{P}<0.001$ and $* * * * \mathrm{P}<0.0001$. 

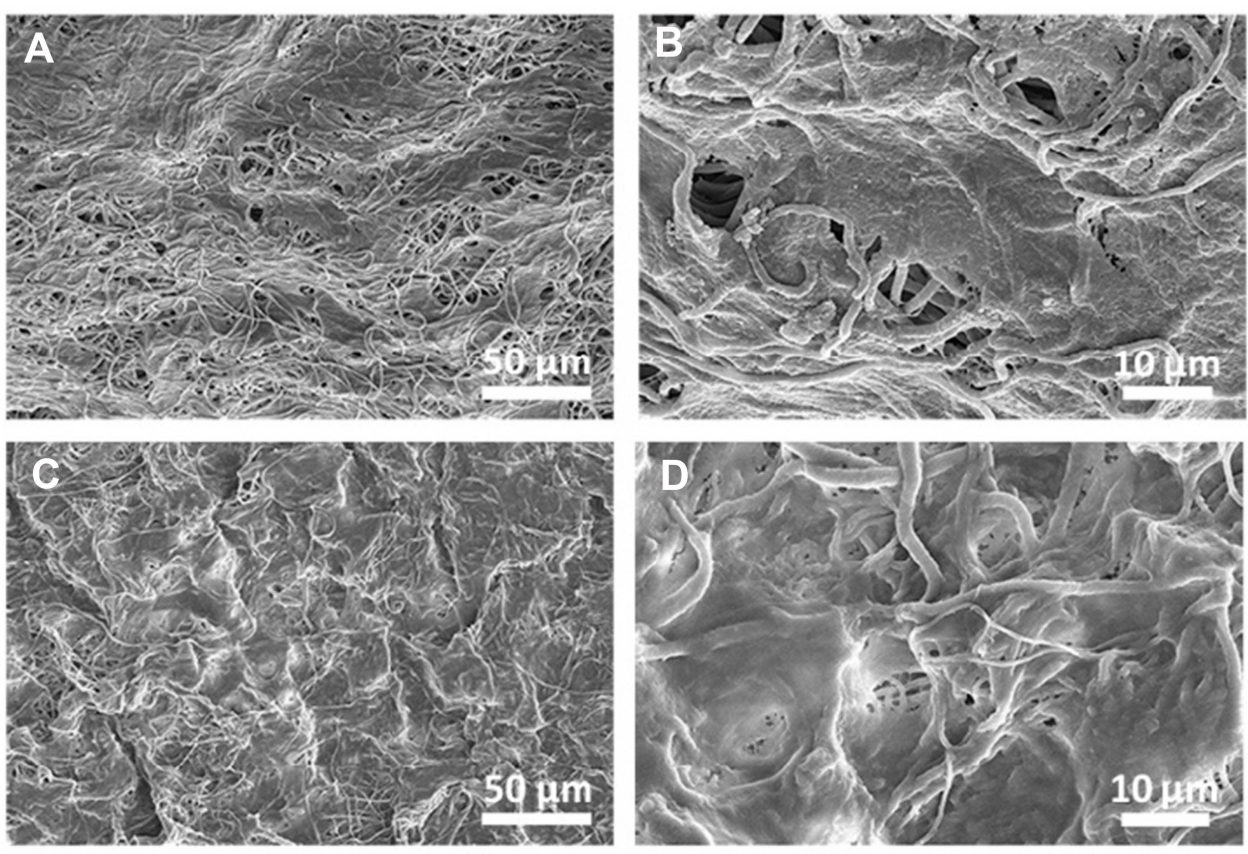

Figure 8 Morphology of hASCs incubated on scaffolds in the presence of osteogenic differentiation media at day I4, (A and B) PLLA/HA/DP scaffolds, (C and D) PLLA/ PEO/HA/DP.

Furthermore, in this study, the adding of PEO to PLLA improved cell viability, ${ }^{38}$ although it's not significant.

\section{Cell Differentiation Assessment} Morphological Assessment Cells on Scaffolds

Morphology of hASCs on the PLLA/HA/DP and PLLA/ $\mathrm{PEO} / \mathrm{HA} / \mathrm{DP}$ nanofibrous scaffolds was investigated during osteogenic differentiation at day 14 (Figure 8). The flat morphology of the hASCs cells on the scaffolds indicated that the scaffolds are biocompatible. Besides, deposition of mineral compounds is intelligibly seen on the scaffolds. ${ }^{39}$ For quantitative measurement of deposited calcium, calcium content assay was also measured at three-time point (7, 14 and 21 days) see Figure 7C.

\section{ALP Activity}

Cell proliferation, extra cellular media (ECM) secretion and mineralization have been introduced as three steps of osteoblast differentiation. Expression of distinguished markers can be used to appraised each level of osteoblast differentiation. In order to study the capability of the nanofibrous scaffolds to support and simplify osteogenic differentiation of hASCs, ALP activity as an early marker of osteogenesis were used. Figure 7B indicated the time period of ALP activity of hASCs seeded on the scaffolds and TCP for 21 days. Figure 7B demonstrated an enhancement in ALP activity for hASCs cultured on the scaffolds and the TCP at day 14 and after that downregulation amount at day 21 . It could be due to transition to ECM mineralization.

Significantly higher ALP activity was observed by hASCs cultured on PLLA/PEO/HA/DP scaffold. This could be related to simultaneous presence of two factors HA and PEO which increases water penetration to scaffolds and cause enhanced release of DPs. ${ }^{37}$ Also, literatures have shown that HA could increase ALP activity. ${ }^{39}$

\section{Ca Content Assay}

Calcium content analysis was utilized as an additional confirmatory test to investigate the hASCs differentiation to osteoblasts. In the osteogenesis process, biomineralization take places in the late phase. Figure $7 \mathrm{C}$ depicted that similar upward trend can be observed for all scaffolds from day 1 to day 21. In each time point, PLLA/PEO/ HA/DP scaffold showed the highest amount of calcium deposition. This could be explained by synergic effect HA and DPs, both factors can differentiate hASCs to osteoblast, as well as, enhance Ca deposition. ${ }^{37,39}$ In addition, PEO as a hydrophilic substance in this scaffold can be dissolved in culture media and enhances the scaffold permeability and lead to the release of both nanoparticles (HA and DPs). ${ }^{32}$ 

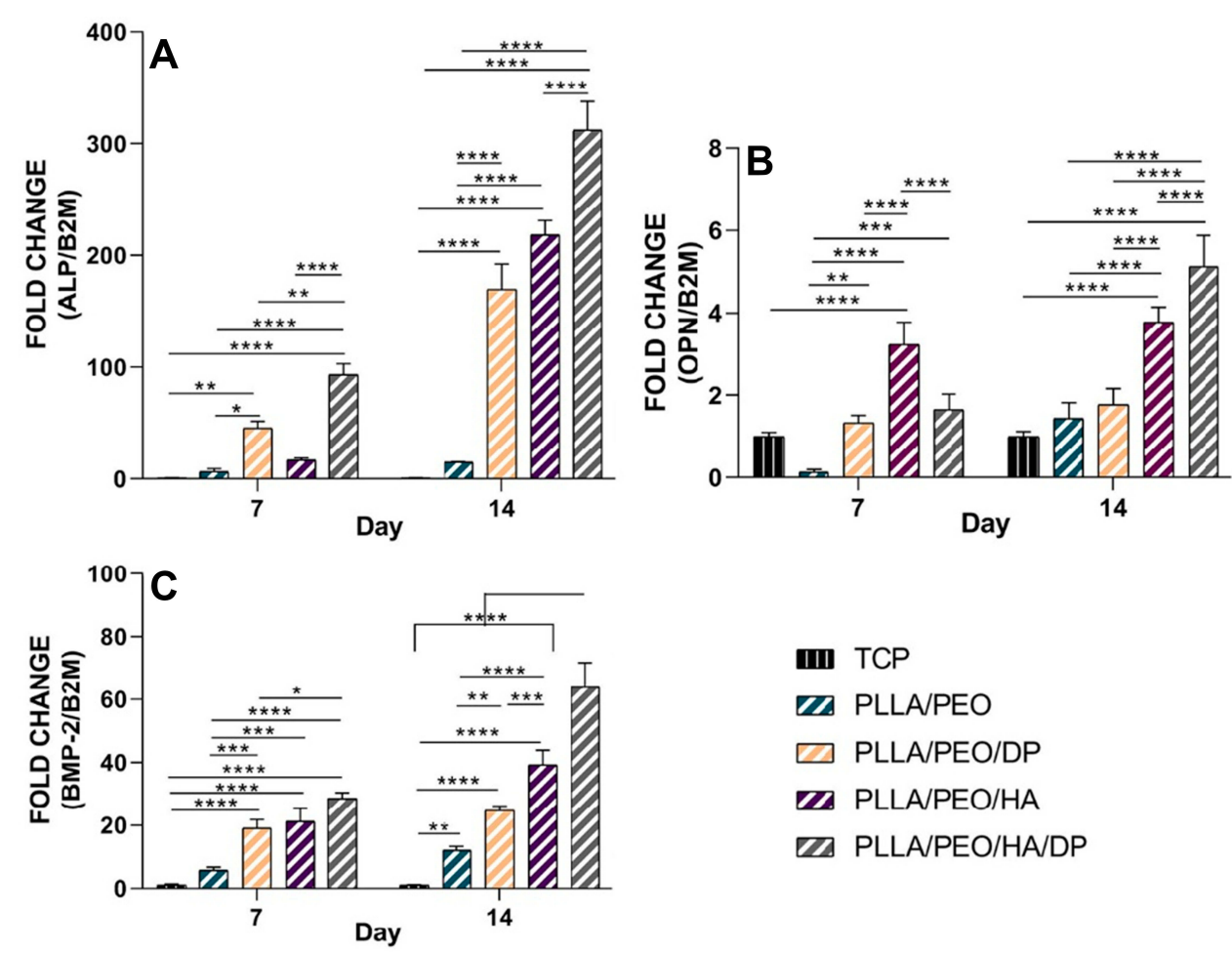

Figure 9 Effect scaffolds containing HA and DPs on the expression osteogenic markers by hASCs at days 7 and I4. Relative gene expression (A) ALP, (B) OPN and (C) BMP-2 by $q R T-P C R$, results were expressed as a mean \pm SD.

Notes: $* \mathrm{P}<0.05, * * \mathrm{P}<0.01$, $* * * \mathrm{P}<0.001$ and $* * * * \mathrm{P}<0.0001$

\section{Quantitative Real-Time PCR Analysis}

In order to further explore hASCs differentiation to osteoblast and their quantitative evaluation, expression level of osteogenic-related genes ALP, BMP-2 and OPN was measured. Figure 9 demonstrated ALP, OPN and BMP-2 mRNA levels for PLLA/PEO, PLLA/PEO/HA, PLLA/PEO/DP and PLLA/PEO/HA/DP scaffolds at days 7 and 14.

All osteogenic markers showed higher expression at day 14 compared to day 7. HA and DPs incorporated in scaffolds enhanced osteogenesis, while the existence of both of them in PLLA/PEO/HA/DP has a synergistic effect and increased expression ALP, OPN and BMP-2 at days 7 and 14 . Moreover, the HA may straightly active signaling pathways relevant to osteogenesis, but HA possibly can increase DPs release and enhanced expression osteogenesis markers for two reasons: (1) By creating holes in the fibers, which in turn enhances the penetration of the water. (2) Its presence creates an alkaline environment in the fibers, resulting in faster hydrolysis of the PLLA ester bonds. ${ }^{37}$

\section{Conclusion}

In this work, MFD utilized for BMP-2 plasmid/PAMAM DPs preparation. MF-prepared DPs had less toxicity compared to bulk prepared NPs. Fabricated PLLA-based nanofibrous scaffolds containing HA and DPs promoted in vitro osteogenesis of hASCs. This study revealed that presence of HA and PEO could improve cell viability. Also, incorporation of HA and DPs enhanced in vitro hASCs differentiation. It can be concluded that MF-prepared DPs and HA loaded in PLLA/PEO nanofibrous scaffold are promising gen delivery carrier. Ultimately, this system is recommended as an efficient gene delivery vehicle for further investigation and in vivo studies.

\section{Acknowledgment}

This study was supported by a grant from the Research Council of Tehran University of Medical Sciences (Grant no. 31591).

\section{Disclosure}

The authors report no conflicts of interest in this work.

\section{References}

1. L Santos J, Pandita D, Rodrigues J, P Pego A, L Granja P, Tomás H. Non-viral gene delivery to mesenchymal stem cells: methods, strategies and application in bone tissue engineering and regeneration. Curr Gene Ther. 2011;11(1):46-57. doi:10.2174/156652311794520102 
2. Steinert AF, Nöth U, Tuan RS. Concepts in gene therapy for cartilage repair. Injury. 2008;39(1):97-113. doi:10.1016/j.injury.2008.01.034

3. Nazir S, Hussain T, Ayub A, Rashid U, MacRobert AJ. Nanomaterials in combating cancer: therapeutic applications and developments. Nanomed Nanotechnol Biol Med. 2014;10(1):19-34. doi:10.1016/j.nano.2013.07.001

4. Zhu K, Guo C, Lai H, Yang W, Wang C. Novel hyperbranched polyamidoamine nanoparticle based gene delivery: transfection, cytotoxicity and in vitro evaluation. Int J Pharm. 2012;423(2):378-383. doi:10.1016/j.jpharm.2011.12.030

5. Hosseinkhani H, Azzam T, Kobayashi H, et al. Combination of 3D tissue engineered scaffold and non-viral gene carrier enhance in vitro DNA expression of mesenchymal stem cells. Biomater. 2006;27 (23):4269-4278. doi:10.1016/j.biomaterials.2006.02.033

6. Niyibizi C, Baltzer A, Lattermann C, et al. Potential role for gene therapy in the enhancement of fracture healing. Clin Orthop Relat Res. 1998;355:S148-S153. doi:10.1097/00003086-199810001-00016

7. Chen D, Zhao M, Mundy GR. Bone morphogenetic proteins. Growth Factors. 2004;22(4):233-241. doi:10.1080/08977190412331279890

8. Jeon O, Song SJ, Kang S-W, Putnam AJ, Kim B-S. Enhancement of ectopic bone formation by bone morphogenetic protein-2 released from a heparin-conjugated poly (L-lactic-co-glycolic acid) scaffold. Biomater. 2007;28(17):2763-2771. doi:10.1016/j.biomaterials.2007.02.023

9. Ashinoff RL, Jr CL C, Galiano RD, et al. Bone morphogenic protein2 gene therapy for mandibular distraction osteogenesis. Ann Plast Surg. 2004;52(6):585-590. doi:10.1097/01.sap.0000123023.28874.1e

10. Yang K, Qin W, Tang H, et al. Polyamidoamine dendrimer-functionalized carbon nanotubes-mediated GFP gene transfection for HeLa cells: effects of different types of carbon nanotubes. $J$ Biomed Mater Res. A. 2011;99(2):231-239. doi:10.1002/jbm.a.33180

11. Kong L, Alves CS, Hou W, et al. RGD peptide-modified dendrimerentrapped gold nanoparticles enable highly efficient and specific gene delivery to stem cells. ACS Appl Mater Interfaces. 2015;7(8):48334843. doi:10.1021/am508760w

12. Luo C, Lü D, Pan J, Long M. Improving the gene transfection in human embryonic stem cells: balancing with cytotoxicity and pluripotent maintenance. ACS Appl Mater Interfaces. 2016;8(13):83678375. doi:10.1021/acsami.6b00353

13. Kim T-I, Seo HJ, Choi JS, et al. PAMAM-PEG-PAMAM: novel triblock copolymer as a biocompatible and efficient gene delivery carrier Biomacromolecules. 2004;5(6):2487-2492. doi:10.1021/bm049563j

14. Li J, Liang H, Liu J, Wang Z. Poly (amidoamine)(PAMAM) dendrimer mediated delivery of drug and pDNA/siRNA for cancer therapy. Int $J$ Pharm. 2018;546(1-2):215-225. doi:10.1016/j.ijpharm.2018.05.045

15. Czarnomysy R, Bielawska A, Bielawski K. Effect of 2nd and 3rd generation PAMAM dendrimers on proliferation, differentiation, and pro-inflammatory cytokines in human keratinocytes and fibroblasts. Int J Nanomedicine. 2019;14:7123. doi:10.2147/IJN.S211682

16. Han H, Chen W, Yang J, et al. Inhibition of cell proliferation and migration through nucleobase-modified polyamidoamine-mediated p53 delivery. Int J Nanomedicine. 2018;13:1297. doi:10.2147/IJN.S146917

17. Debus H, Beck-Broichsitter M, Kissel T. Optimized preparation of pDNA/poly (ethylene imine) polyplexes using a microfluidic system. Lab Chip. 2012;12(14):2498-2506. doi:10.1039/c2lc40176b

18. Demello AJ. Control and detection of chemical reactions in microfluidic systems. Nature. 2006;442(7101):394. doi:10.1038/nature05062

19. Ho Y-P, Grigsby CL, Zhao F, Leong KW. Tuning physical properties of nanocomplexes through microfluidics-assisted confinement. Nano Lett. 2011;11(5):2178-2182. doi:10.1021/n1200862n

20. Koh CG, Kang X, Xie Y, et al. Delivery of polyethylenimine/DNA complexes assembled in a microfluidics device. Mol Pharm. 2009;6 (5):1333-1342. doi:10.1021/mp900016q

21. Wilson DR, Mosenia A, Suprenant MP, et al. Continuous microfluidic assembly of biodegradable poly (beta-amino ester)/DNA nanoparticles for enhanced gene delivery. J Biomed Mater Res A. 2017;105 (6): 1813-1825. doi:10.1002/jbm.a.36033
22. Telgerd MD, Sadeghinia M, Birhanu G, et al. Enhanced osteogenic differentiation of mesenchymal stem cells on metal-organic framework based on copper, zinc, and imidazole coated poly-l-lactic acid nanofiber scaffolds. J Biomed Mater Res. A. 2019;107(8):1841-1848. doi:10.1002/jbm.a.36707

23. Holladay C, Keeney M, Greiser U, Murphy M, O’Brien T, Pandit A. A matrix reservoir for improved control of non-viral gene delivery. J Control Release. 2009;136(3):220-225. doi:10.1016/j.jconrel.2009.02.006

24. Kuroda S, Kondo H, Ohya K, Kasugai S. A new technique with calcium phosphate precipitate enhances efficiency of in vivo plasmid DNA gene transfer. $J$ Pharmacol Sci. 2005;97(2):227-233.

25. Hasani-Sadrabadi MM, Hajrezaei SP, Emami SH, et al. Enhanced osteogenic differentiation of stem cells via microfluidics synthesized nanoparticles. Nanomed Nanotechnol Biol Med. 2015;11(7):18091819. doi:10.1016/j.nano.2015.04.005

26. Esfand R, Tomalia D. Laboratory synthesis of poly (amidoamine)(PAMAM) dendrimers. In: Scheirs J, Fréchet JM, Tomalia D, editors.Dendrimer and Other Dendritic Polymers. 2001:587-604. doi:10.1002/0470845821.ch25

27. Zakeri A, Kouhbanani MAJ, Beheshtkhoo N, et al. Polyethyleniminebased nanocarriers in co-delivery of drug and gene: a developing horizon. Nano Rev Exp. 2018;9(1):1488497. doi:10.1080/20022727.2018.1488497

28. Iliescu C, Mărculescu C, Venkataraman S, Languille B, Yu H, Tresset G. On-chip controlled surfactant-DNA coil-globule transition by rapid solvent exchange using hydrodynamic flow focusing. Langmuir. 2014;30(44):13125-13136. doi:10.1021/la5035382

29. Maiti PK, Bagchi B. Diffusion of flexible, charged, nanoscopic molecules in solution: size and $\mathrm{p} \mathrm{H}$ dependence for PAMAM dendrimer. J Chem Phys. 2009;131(21):214901. doi:10.1063/1.3266512

30. Voordouw G, Kam Z, Borochov N, Eisenberg H. Isolation and physical studies of the intact supercoiled: the open circular and the linear forms of CoIE1-plasmid DNA. Biophys Chem. 1978;8(2):171189. doi:10.1016/0301-4622(78)80008-8

31. Chen S, Zhang H, Shi X, Wu H, Hanagata N. Microfluidic generation of chitosan/CpG oligodeoxynucleotide nanoparticles with enhanced cellular uptake and immunostimulatory properties. Lab Chip. 2014;14(11):1842-1849. doi:10.1039/c4lc00015c

32. Dai R, Lim L-T. Release of allyl isothiocyanate from mustard seed meal powder entrapped in electrospun PLA-PEO nonwovens. Food Res Int. 2015;77:467-475. doi:10.1016/j.foodres.2015.08.029

33. Fu C, Bai H, Zhu J, et al. Enhanced cell proliferation and osteogenic differentiation in electrospun PLGA/hydroxyapatite nanofibre scaffolds incorporated with graphene oxide. PLoS One. 2017;12(11): e0188352. doi:10.1371/journal.pone.0188352

34. Liu X, Gao G, Dong L, Ye G, Gu Y. Correlation between hydrogenbonding interaction and mechanical properties of polyimide fibers. Polym Adv Technol. 2009;20(4):362-366. doi:10.1002/pat.1232

35. Saha D, Samal SK, Biswal M, Mohanty S, Nayak SK. Preparation and characterization of poly (lactic acid)/poly (ethylene oxide) blend film: effects of poly (ethylene oxide) and poly (ethylene glycol) on the properties. Polym Int. 2019;68(1):164-172. doi:10.1002/pi.5718

36. Yang Y, Li X, Cheng L, et al. Core-sheath structured fibers with pDNA polyplex loadings for the optimal release profile and transfection efficiency as potential tissue engineering scaffolds. Acta Biomater. 2011;7(6):2533-2543. doi:10.1016/j.actbio.2011.02.031

37. Nie H, Wang C-H. Fabrication and characterization of PLGA/HAp composite scaffolds for delivery of BMP-2 plasmid DNA. J Control Release. 2007;120(1-2):111-121. doi:10.1016/j.jconrel.2007.03.018

38. Cui W, Zhu X, Yang Y, Li X, Jin Y. Evaluation of electrospun fibrous scaffolds of poly (dl-lactide) and poly (ethylene glycol) for skin tissue engineering. Mater Sci Eng C. 2009;29(6):1869-1876. doi:10.1016/j. msec.2009.02.013

39. Seyedjafari E, Soleimani M, Ghaemi N, Shabani I. Nanohydroxyapatite-coated electrospun poly (1-lactide) nanofibers enhance osteogenic differentiation of stem cells and induce ectopic bone formation. Biomacromolecules. 2010;11(11):3118-3125. doi:10. 1021/bm1009238 


\section{Publish your work in this journal}

The International Journal of Nanomedicine is an international, peerreviewed journal focusing on the application of nanotechnology in diagnostics, therapeutics, and drug delivery systems throughout the biomedical field. This journal is indexed on PubMed Central, MedLine, CAS, SciSearch ${ }^{\mathbb{R}}$, Current Contents ${ }^{\mathbb{B}} /$ Clinical Medicine,
Journal Citation Reports/Science Edition, EMBase, Scopus and the Elsevier Bibliographic databases. The manuscript management system is completely online and includes a very quick and fair peer-review system, which is all easy to use. Visit http://www.dovepress.com/ testimonials.php to read real quotes from published authors. 